\title{
Stress and oesophageal motility in normal subjects and patients with irritable bowel syndrome
}

\author{
R C S AYRES, D A F ROBERTSON, K NAYLOR, AND C L SMITH \\ From the Department of Medicine 2, Southampton General Hospital, Southampton, Hampshire
}

Summary Patterns of oesophageal motility were recorded in 17 healthy volunteers and 12 patients with the irritable bowel syndrome. Recordings were taken at rest and under stress by hyperventilation, a dichotic hearing challenge and a cold pressor test. In healthy volunteers the dichotic hearing challenge was associated with a significant increase in the mean amplitude of oesophageal peristalsis from $69.9 \mathrm{mmHg}$ to $82.4 \mathrm{mmHg}(\mathrm{p}<0.01)$ and in the percentage of simultaneous waves from $9.7 \%$ to $24 \cdot 5 \%(p<0 \cdot 01)$. The cold pressor test increased the peristaltic amplitude from $69.9 \mathrm{mmHg}$ to $87 \cdot 1$ $\mathrm{mmHg}(\mathbf{p}<0 \cdot 001)$ and the percentage of simultaneous waves from $9 \cdot 7 \%$ to $34 \cdot 4 \%(p<0 \cdot 01)$. Both manoeuvres were associated with increases in pulse and blood pressure. In patients with irritable bowel syndrome, the resting mean oesophageal peristaltic amplitude was higher than that seen in normal volunteers $(95.9 \mathrm{mmHg} v 69.9 \mathrm{mmHg} p<0.05)$. Changes in oesophageal motility during stress were similar in these patients to those seen in normal subjects although the changes were not significant. This study refutes the hypothesis that symptoms of irritable bowel syndrome and their association with stress are attributable to increased sensitivity of oesophageal motility to disruption by stressful stimuli.

There is a complex relationship between stress, gastrointestinal motility and the irritable bowel syndrome. Patients with the irritable bowel syndrome and those with nutcracker oesophagus have significantly higher scores in assessments of anxiety, depression, and neurosis than controls. ' In one study, up to $73 \%$ of patients with the irritable bowel syndrome were found to be depressed. ${ }^{3}$ Patients with the irritable bowel syndrome frequently report that their symptoms are subjectively worse when they are under stress.

Stressful stimuli have been shown to disrupt upper gastrointestinal motility in a variety of ways, including increased mean oesophageal peristaltic amplitude, ${ }^{4}$ rate of gastric emptying and small bowel transit in irritable bowel syndrome, ${ }^{\circ}$ and in normal subjects, ${ }^{7}$ and increased upper oesophageal sphincter pressure. ${ }^{*}$

Irritable bowel syndrome commonly presents with

Address for correspondence: Dr D A F Robertson, Department of Medicine, Royal United Hospital, Combe Park, Bath BA1 3WG.

Accepted for publication 14 March 1989. oesophageal symptoms" and is associated with abnormal gastrointestinal function, including oesophageal dysmotility,"' abnormal small bowel motility, ${ }^{112}$ and abnormal colonic motility and myoelectrical activity. ${ }^{13}$ Disorders of gastrointestinal motility are commonly seen in patients with symptoms referable to the gut such as abdominal and chest pain and such symptoms may be artificially induced by balloon distension of the oesophagus, small bowel, ${ }^{14}$ or colon. ${ }^{15}$

In view of the known association between the irritable bowel syndrome and neurosis and the exacerbation of symptoms by stress in patients with irritable bowel syndrome, it is postulated that stress may cause symptoms because of increased susceptibility to symptomatic gastrointestinal dysmotility.

We have measured oesophageal motility in healthy volunteers and patients with irritable bowel syndrome at rest and under three different stressful stimuli, namely hyperventilation, dichotic hearing challenge and the cold pressor test to assess whether patients with irritable bowel syndrome are more susceptible to stress induced dysmotility. 


\section{Methods}

\section{SUB JECTS}

Healthy volunteers were recruited to the study from members of hospital staff and medical students. Patients were recruited from the gastroenterology outpatient clinic. The inclusion criterion was a diagnosis of irritable bowel syndrome made by a consultant gastroenterologist and after appropriate investigations to exclude more serious pathology. Patients had either painless diarrhoea, or abdominal pain with bloating. All subjects entered the study after informed consent. The study was approved by our local ethical committee.

Seventeen healthy volunteers with mean age 23.8 years (21-39) (nine men) were recruited to the study along with 12 patients with irritable bowel syndrome with mean age $42 \cdot 7$ years (22-63) (six men).

\section{MANOMETRY}

Oesophageal manometry was performed using a triple lumen oesophageal catheter passed through the nasopharynx and positioned with the lower perfusion port $5 \mathrm{~cm}$ proximal to the lower oesophageal sphincter. This was connected to a HewlettPackard transducer and recorder.

PULSE AND BLOOD PRESSURE

The pulse was measured by electrocardiography and the blood pressure by sphygmomanometer before and after the rest period and after each swallow during hyperventilation, dichotic hearing challenge and the cold pressor test.

\section{RESTING READINGS}

After a five minute rest period pulse and blood pressure readings were measured. Subjects were then asked to take $104 \mathrm{ml}$ swallows of water over a 10 minute period during which time oesophageal manometry was recorded.

HYPERVENTILATION

Subjects were instructed to hyperventilate for 15 seconds or until dizziness was felt. After this a $4 \mathrm{ml}$ swallow was given and oesophageal recordings taken. Subjects then hyperventilated for a further 10 seconds followed by another wet swallow and for a final 10 seconds followed by the final swallow. Pulse and blood pressure were recorded after each swallow.

DICHOTIC HEARING CHALIENGE

This was performed using a portable stereo cassette player with headphones. The cassette tape contained separate narratives on left and right channels heard simultaneously. The subject was given a questionnaire alternating between the two narratives. Manometry was performed as at rest. Pulse and blood pressure were recorded after each swallow. Ten measurements were performed, and this part of the study lasted for 15-20 minutes.

COLD PRESSOR TEST

This was undertaken using a large bucket filled with water and ice. The subject was instructed to immerse the left forearm into the water for a period of one minute and to remove it for 15 seconds to a maximum of eight repeats, depending on compliance. Each subject was reassured that should the procedure become too unpleasant that they could stop at any time. After each immersion of the arm the subject was given a wet swallow and oesophageal manometry performed. Pulse and blood pressure was recorded after each swallow.

Stressful stimuli were applied in the following order: hyperventilation, dichotic hearing challenge, cold pressor test, with five minute rest between measurements. Pulse and blood pressure readings were found to return to baseline within this period in all subjects.

STATISTICAL ANALYSIS

Pulse, systolic and diastolic blood pressure were recorded as described above for each of the four phases of the test, namely at rest, during hyperventilation, dichotic hearing challenge, and during cold pressor stress. Oesophageal manometry tracings were analysed for mean amplitude of peristalsis along

Table 1 Response of pulse, blood pressure, and four parameters of oesophageal function in healthy volunteers to each stressful stimulus ( $n=17$, mean age $23 \cdot 8$ yr (21-39) $M: F=1: I)$

\begin{tabular}{|c|c|c|c|c|c|c|c|}
\hline Test & Pulse/min & Syst BP/mmHg & Diast $\mathrm{BP} / \mathrm{mmHg}$ & $A M P / m m H g$ & Simult $/ \%$ & Multil\% & Low amp/\% \\
\hline Control & $69 \cdot()(51-100)$ & $118 \cdot 6(95-160)$ & $71 \cdot 8(55-98)$ & $69.9(52-84)$ & $9 \cdot 7(0-5())$ & $15.4(0-86)$ & $39.9(()-81)$ \\
\hline Hyperv & $88.5(62-125) \dagger$ & $120 \cdot 8(95-165)$ & $73 \cdot 1(50-100)$ & $72 \cdot 6(38-99)$ & $11 \cdot 7(0-10(0)$ & $22 \cdot 2(0-10())$ & $36 \cdot 6(0-10(0))$ \\
\hline Dichotic & $73 \cdot 8(51-99)^{*}$ & $123.7(102-173)^{*}$ & $76.8(59-1(0))^{*}$ & $82.4(34-101)^{*}$ & $24 \cdot 5(6-51)^{*}$ & $17 \cdot 4(0-56)$ & $50 \cdot 5(18-74)$ \\
\hline Cold Pre & $75 \cdot 1(56-113) \dagger$ & $138 \cdot 3(106-185) \dagger$ & $94 \cdot 8(70-123) \ddagger$ & $87 \cdot 1(72-102) \div$ & $34 \cdot 4(7-63) \dagger$ & $20 \cdot 1(0-62)$ & 5()$\cdot 7(27-81)$ \\
\hline
\end{tabular}

Difference from control phase: ${ }^{*} \mathrm{p}<0.05 ; \dagger \mathrm{p}<0.01 ; \neq \mathrm{p}<0.001$. 
with number of simultaneous waves, low amplitude waves and multimorphic waves, each expressed as a percentage of the total number of waves seen for each phase of the study.

Results for healthy volunteers and patients were analysed separately and results expressed as a mean. Comparisons of results between the various phases of the study for a particular group and between groups was made using a 2-tailed Mann-Whitney signs test for non-parametric data.

\section{Results}

HEALTHY VOLUNTEERS

Pulse and blood pressure changes along with oesophageal manometric data in both subject groups are seen in Table 1. Some individuals appeared to be hypertensive at 'rest', though this may be attributable to the baseline stress involved in the procedure, before any further measures were applied to further stress the subject.

Hyperventilation was associated with an increase in pulse from $69.0 \mathrm{bpm}$ to $88.5 \mathrm{bpm}(\mathrm{p}<0.01)$ but no difference in systolic or diastolic blood pressure. None of the parameters of oesophageal function were significantly affected by hyperventilation.

The dichotic hearing challenge produced significant increases in pulse from $69 \mathrm{bpm}$ to $73.8 \mathrm{bpm}$ $(\mathrm{p}<0.05)$, systolic BP from $118.6 \mathrm{mmHg}$ to 123.7 $\mathrm{mmHg}(\mathrm{p}<0.05)$, and diastolic BP from $71.8 \mathrm{mmHg}$ to $76.8 \mathrm{mmHg}(\mathrm{p}<0.05)$. A significant increase was seen in amplitude of oesophageal peristalsis from $69.9 \mathrm{mmHg}$ to $82.4 \mathrm{mmHg}(\mathrm{p}<0 .(01)$ and also in the percentage of simultaneous waves from $9.7 \%$ to $24.5 \%(\mathrm{p}<0 \cdot 01)$.

The cold pressor test similarly produced significant increases in pulse $69 \mathrm{bpm}$ to $75.1 \mathrm{bpm}(\mathrm{p}<0.01)$, systolic BP from $118.6 \mathrm{mmHg}$ to $138.3 \mathrm{mmHg}$ $(\mathrm{p}<0.01)$ and diastolic BP from $71.8 \mathrm{mmHg}$ to 94.8 $\mathrm{mmHg}(\mathrm{p}<0.001)$. An increased amplitude of peristalsis was seen from $69.9 \mathrm{mmHg}$ to $87.1 \mathrm{mmHg}$ $(\mathrm{p}<0.001)$ and in the percentage of simultaneous waves from $9 \cdot 7 \%$ to $34 \cdot 4 \%(p<0 \cdot() 1)$.

The percentage of multimorphic waves and low amplitude waves was not significantly affected by any of the stress manocuvres although a tendency was seen for increased numbers of low amplitude waves during the dichotic heating challenge and during the cold pressor test.

IRRITABIIE BOWEI. SYNDROME PATIIENTS

Pulse and blood pressure changes in the irritable bowel group are seen in Table 2. The cold pressor test produced significant increases in systolic and diastolic BP only. Trends similar to those seen in normal subjects were evident in measurements of pulse rate during hyperventilation and of blood pressure during the dichotic hearing challenge but the changes were not significant. Patients with irritable bowel syndrome showed similar changes to healthy voluntecrs in measurement of mean amplitude of oesophageal peristalsis between the various types of stress and a trend towards an increased percentage of simultaneous waves was seen during the cold pressor test but unlike the healthy volunteer group, these changes did not achieve statistical significance. No trend was seen in the percentage of low amplitude or multimorphic waves recorded.

Comparing results between the two groups reveals the following statistically significant differences. Resting pulse rate and pulse rate during hyperventilation were both significantly higher in the patient group. A lower percentage of simultaneous waves was recorded during the dichotic hearing test in patients compared with normal subjects $(5.4 \% \mathrm{v}$, $24.5 \%, p<0 \cdot(01)$. A low percentage of low amplitude waves was seen in patients at rest $(21.7 \%, 39.9 \%$, $\mathrm{p}<0.05)$, during dichotic hearing challenge $(16.9 \% \mathrm{v}$ $50.5 \%, \mathrm{p}<0.01)$, and during cold pressor test $(31.9 \%$ . $50.7 \%, \mathrm{p}<0 .(05)$.

\section{Discussion}

We have demonstrated an increased mean amplitude of oesophageal peristalsis along with an increased proportion of spontaneous, simultaneous, nonpropulsive waves in normal subjects in response to a dichotic hearing challenge and the cold pressor test.

Table 2 Response of pulse, blood pressure, and four parameters of oesophageal function in patients with irritable bowel syndrome to each stressful stimulus ( $n=12$, mean age 42.7 yr (22-63) $M: F=1: 1)$

\begin{tabular}{|c|c|c|c|c|c|c|c|}
\hline Test & Pulse/min & Syst BP/mmHg & Diast $\mathrm{BP} / \mathrm{mmHg}$ & $A M P / m m H g$ & Simult $/ \%$ & Multi/\% & Low amp/\% \\
\hline Control & $73 \cdot 4(50-88)$ & $138 \cdot 4(113-180)$ & $79 \cdot 1(63-93)$ & $95 \cdot 9(38-130)$ & $5 \cdot 7(0-25)$ & $5 \cdot 9(0-18)$ & $21 \cdot 7(0-40)$ \\
\hline Hyperv & $80 \cdot 7(53-103)$ & $138 \cdot 2(105-170)$ & $78 \cdot 5(63-100)$ & $103 \cdot 5(40-198)$ & $10 \cdot 4(0-63)$ & $2 \cdot 4(0-13)$ & $30 \cdot 7(6-66)$ \\
\hline Dichotic & $76 \cdot 1(50-93)$ & $137 \cdot 7(113-162)$ & $81 \cdot 9(70-92)$ & $116 \cdot 0(48-178)$ & $5 \cdot 4(0-23)$ & $10 \cdot 0(0-42)$ & $16 \cdot 9(0-29)$ \\
\hline Cold Pre & $76 \cdot 6(51-102)$ & $158 \cdot 2(130-187)^{*}$ & $93.7(82-102)^{*}$ & $112 \cdot 5(50-181)$ & $20 \cdot 1(0-55)$ & $10 \cdot 0(0-30)$ & $31 \cdot 9(0-66)$ \\
\hline
\end{tabular}

Difference from control phase: ${ }^{*} \mathrm{p}<0 \cdot 01$. 
This was associated with a marked pressor response. Hyperventilation did not alter any of the parameters of oesophageal motility. Similarly it did not affect systolic or diastolic blood pressure and was not subjectively appreciated by subjects as being as stressful as either the dichotic hearing challenge nor the cold pressor test. It is likely therefore that this particular manoeuvre did not constitute a significant stressful stimulus.

A similar tendency to increased mean oesophageal peristaltic amplitude and increased spontaneous activity was seen in patients with irritable bowel syndrome although the changes before and after the stressful stimulus were not statistically significantly different.

The relatively diminished response of oesophageal mean peristaltic amplitude to stress in the patient group may have been related to higher resting values $(95.9 \mathrm{mmHg} \vee 69.9 \mathrm{mmHg}, \mathrm{p}<0.05)$ as compared with healthy volunteers. The two groups were not age matched. The healthy volunteer group had a mean age of $23.8 \mathrm{yr}$, that of the irritable bowel group being $42.7 \mathrm{yr}(\mathrm{p}<0.01)$. The difference in resting mean peristaltic amplitudes between the two groups may have been contingent upon this although it has been shown that oesophageal peristaltic amplitude falls progressively with age. ${ }^{\text {in }}$ An alternative explanation is that the patient group suffered greater stress than healthy volunteers as a result of coming into hospital and having oesophageal manometry performed at rest, and that the higher resting values for mean peristaltic amplitude and the relatively blunted response to the various stress manoeuvres resulted from this heightened background stress. This would be consistent with results of psychometric assessments performed in irritable bowel syndrome patients. A third possibility is that patients with irritable bowel syndrome may have a reduced susceptibility to stressful stimuli than normal subjects.

This study does not support the hypothesis that symptoms of irritable bowel syndrome are attributable to increased sensitivity of oesophageal motility to disruption by stressful stimuli. We have shown that oesophageal function is labile in normal subjects and in irritable bowel syndrome and there appears to be no excess dysmotility patients with the irritable bowel syndrome. It is possible that the higher resting oesophageal mean peristaltic amplitude seen in patients with irritable bowel syndrome is related to heightened background stress.

\section{References}

I Richter JE, Obrecht WF, Bradley LA, Young LD, Anderson KO. Psychological comparison of patients with nutcracker ocsophagus and irritable bowel syndrome. Dig Dis Sci 1986; 31: 131-8.

2 Whitchead WE, Engel BT, Schuster MM. Irritable bowel syndrome. Physiological and psychological differences between diarrhoca-predominant and constipation-predominant patients. Dig Dis Sci 1980; 25: 404-13.

3 Hislop IG. Psychological significance of the irritable colon syndrome. Gut 1971: 12: 4.52-7.

4 Obrecht WF. Richter JE. Stress in the healthy oesophagus [Abstract]. Dig Dis Sci 1984; 29: 568A.

5 Thompson DG, Richelson E, Malagelada JR. Perturbation of upper GI function by cold stress. Gut 1983; 24: 277-83.

6 Cann PA, Read NW, Cammack J, et al. Psychological stress and the passage of a standard meal through the stomach and small intestine in man. Gut 1983; 24: 23640 .

7 Kumar D. Wingate DL. The irritable bowel syndrome: a paroxysmal motor disorder. Lancet 198.5; ii: 973-7.

8 Cook IJ, Dent J. Shannon S, Collins SM. Measurement of UES pressurc - Effect of acute cmotional stress. Gastroenterology 1987; 93: 526-32.

9 Watson WC, Sullivan SN, Corkc M, Rush D. Incidence of ocsophagcal symptoms in paticnts with irritable bowel syndrome [Abstract]. Gut 1976; 17: 827A.

10) Whorwell PJ, Clouter C. Smith CL. Ocsophageal motility in the irritable bowel syndrome. Br Med J 1981; 282: $1101-2$.

11 Holdstock DJ, Misicwicz JJ, Waller SL. Obscrvations on the mechanisms of abdominal pain. Gut 1969; 10: 1931.

12 Thompson DG, Laidlow JM, Wingate DL. Abnormal small-bowel motility demonstrated by radiotelemetry in a patient with irritable colon. Lancet 1979; ii: 1321-3.

13 Snape WJ, Carlson GM. Cohen S. Colonic myoelectrical activity in the irritable bowel syndrome. Gastroenterology 1970; 70: 326-30.

14 Moriarty KJ, Dawson AM. Functional abdominal pain: further evidence that the whole gut is affected. Br Med J 1982; 284: 167()-2.

15 Ritchic JA. Pain from distension of the pelvic colon by inflating a balloon in the irritable bowel syndrome. Gut 1973; 14: 125-32.

16 Hollis JB, Castell DO. Esophageal function in clderly men: a new look at presbyesophagus. Ann Intern Med 1974; 80: $371-4$. 